\title{
COMUNICAÇÃO CIENTÍFICA E O PAPEL DOS PERIÓDICOS CIENTÍFICOS NO DESENVOLVIMENTO DAS CIÊNCIAS
}

\author{
SCHOLARLY COMMUNICATION AND THE ROLE OF SCIENTIFIC JOURNALS IN \\ THE DEVELOPMENT OF SCIENCES
}

Jorge Santa Anna

Recebido em: 11-02-2019

Aceito em: 31-03-2019

\begin{abstract}
Resumo
Este estudo contempla um recorte de uma pesquisa mais aprofundada sobre portais de periódicos eletrônicos, cujo objetivo do presente artigo é demonstrar a importância da comunicação científica no desenvolvimento das ciências e o papel desempenhado pelos periódicos científicos nesse processo. Ao longo do texto, define e caracteriza-se o processo de comunicação científica; relaciona o processo da comunicação com o desenvolvimento das ciências; e discorre o papel desempenhado pelos periódicos científicos no âmbito da comunicação científica, apresentando alguns desafios e expectativas inerentes a esse tipo de comunicação. $\mathrm{O}$ estudo caracteriza-se como pesquisa descritiva, bibliográfica e de abordagem dedutiva, recorrendo à consulta a livros e artigos científicos que versam sobre a temática em questão. Confirmou-se que os periódicos científicos continuam sendo os principais meios de comunicação científica utilizados em todas as áreas do conhecimento, sendo que o uso das tecnologias digitais contribui para melhorar o processo de comunicação, como também proporciona maior visibilidade das descobertas científicas e maior aproximação entre os diversos personagens envolvidos no processo de comunicação, disseminação e uso das informações científicas. O processo de comunicação científica é beneficiado com o uso dos periódicos eletrônicos, sobretudo no que tange à rapidez e integração dos fluxos de comunicação. Sugere-se a realização de estudo futuro sobre modelos para construção de portais eletrônicos, como também a disseminação dessas publicações e a relações com os públicos-alvo, enfocando na estruturação das plataformas digitais e no comportamento e uso das informações pelos usuários.
\end{abstract}

Palavras-chave: Pesquisa científica. Comunicação científica. Fluxo da comunicação científica. Periódicos científicos.

\begin{abstract}
The purpose of this paper is to demonstrate the importance of scientific communication in the development of sciences and the role played by scientific journals in this process. Throughout the text, defines and characterizes the process of scientific communication; relates the communication process to the development of science; and discusses the role played by scientific journals in the context of scientific communication, presenting some challenges and expectations inherent in this type of communication. The study is characterized as a descriptive, bibliographical and deductive approach, using the consultation of books and scientific articles that deal with the subject matter in question. It has been confirmed that scientific journals continue to be the main means of scientific communication used in all areas of knowledge, and the use of digital technologies contributes to improving the communication process, as well as providing greater visibility of scientific discoveries and greater approach between the various characters involved in the process of communication, dissemination and use of scientific information. The process of scientific communication is benefited by the use of electronic journals, especially as regards the speed and integration of communication flows. It is suggested to carry out a future study on models for the construction of electronic portals, as well as the dissemination
\end{abstract}

\footnotetext{
${ }^{\text {I } M e s t r a n d o ~ d o ~ P r o g r a m a ~ d e ~ P o ́ s-G r a d u a c ̧ a ̃ o ~ e m ~ G e s t a ̃ o ~ e ~ O r g a n i z a c ̧ a ̃ o ~ d o ~ C o n h e c i m e n t o ~ d a ~ U F M G ~-~}$ 
of these publications and relations with target audiences, focusing on the structuring of digital platforms and users' behavior and use of information.

Keywords: Scientific research. Scientific communication. Flow of scientific communication. Scientific journals.

\section{INTRODUÇÃO}

O desenvolvimento das ciências tem sido marcado por constantes mudanças, as quais são fruto das próprias conquistas, descobertas e inovações decorridas do trabalho metodológico, consistente, confiável e fidedigno realizado pelas diversas comunidades ou grupos existentes nas mais diferenciadas áreas do saber humano.

Em grande parte, é graças à rigorosa metodologia estabelecida e ao constante, seguro e minucioso processo avaliativo, características essas marcantes das ciências, que as mudanças são provocadas, tendo em vista promoverem melhorias e qualidade de vida ao ser humano e sua interação com o meio natural e social em que vive.

Portanto, o que particulariza a atividade científica das demais atividades realizadas pelo ser humano, diz respeito à veracidade das informações analisadas e contextualizadas pelos pesquisadores, à legitimidade dessas informações, e, por decorrência, a confiabilidade que essas informações fornecem a um número expressivo de indivíduos, de modo que essas informações, pautadas em paradigmas específicos, passam a ser comungadas e compartilhadas entre especialistas, permitindo, dessa forma, a evolução do conhecimento.

No intuito de viabilizar descobertas e produção de conhecimento, no decurso do processo científico, conjugam-se diversas atividades, em um percurso extenso e contínuo, formado por diversas etapas, manifestadas em diferentes canais de comunicação, envolvendo diferentes atores ou personagens. Trata-se de um processo sistematizado e integrado, que perpassa desde o surgimento das ideias e indagações dos cientistas, até o momento em que elas são comprovadas, validadas e comunicadas, a ponto de serem disponibilizadas para uso.

Em linhas gerais, no decurso desse processo, as informações vão sendo aperfeiçoadas, de modo que os resultados advindos das pesquisas realizadas são compartilhados, estando sujeitos a ações avaliativas e, por conseguinte, garantindo melhoria contínua e excelência dos resultados esperados. O contínuo fluxo das informações científicas que permeiam a atividade de investigação constitui o processo de comunicação científica, processo esse essencial para garantir fidedignidade e consistência das descobertas.

Assim, a comunicação científica representa um dos pilares básicos e mais importante para as ciências, pois ela garante, além da comprovação das descobertas, a sua aceitação por pares e, como consequência, sua divulgação e legitimidade em meio aos grupos que comungam de ideias semelhantes, por decorrência, essas descobertas são compartilhadas, divulgadas e utilizadas em benefício da sociedade.

Nesse âmbito, o processo científico deve proporcionar confiabilidade, uma vez que é submetido à avaliação por pares, proporcionando um sistema veicular de comunicação e, desse processo, resulta-se na literatura especializada de uma determinada área de conhecimento (MUELLER, 2003a). Para produção dessa literatura, segundo Meadows (1999), a comunicação científica manifesta-se como o coração da ciência, pois as informações, ao serem comunicadas, devem ser analisadas e aceitas, o que confere sua veracidade, legitimidade e confiabilidade.

Por constituir-se como um processo dinâmico e complexo, o processo de comunicação científica é realizado por meio de canais formais quanto informais de comunicação (MEADOWS, 1999; MUELLER, 2003a), no entanto, os canais formais, segundo esses autores, sobretudo aqueles que proporcionam um menor tempo na divulgação dos resultados de pesquisa, mesmo que esses sejam de natureza preliminar, como os periódicos científicos, desempenham um papel de destaque entre pesquisadores quando do processo de aprimoramento e melhoria das pesquisas.

Com efeito, evidencia-se que o processo de produção científica atrelado à comunicação 
científica assume um valor essencial no aprimoramento da qualidade de vida e do bem-estar do ser humano enquanto elemento da sociedade. Por isso, a comunicação científica e as contribuições dos periódicos científicos nesse processo têm sido temas recorrentes na literatura, despertando diversas reflexões e interesses de pesquisa a serem desenvolvidas e compartilhadas por todas as áreas do conhecimento.

Autores como Garvey e Griffith (1972), Meadows (1999), Mueller (2003a, 2006), Samagaia (2016) e Targino (2000) são alguns que se dedicaram à reflexão sobre a importância e o desenvolvimento das ciências, enfocando no papel desempenhado pelo processo de comunicação científica. Por sua vez, Fachin e Hillesheim (2006), Garrido e Rodrigues (2010), Houghton (1975), Mueller (2003b), Rodrigues e Fachin (2008), Targino (2001) correspondem a alguns teóricos que se debruçaram sobre a relação ou contribuição dos periódicos científicos no contexto da comunicação científica.

Portanto, com a interferência dos periódicos científicos no progresso das ciências e as mudanças que esses meios de comunicação atravessam ao longo do tempo, instiga-se a realização de uma pesquisa mais aprofundada, a ser realizada posteriormente, sobre a função atual desempenhada pelos periódicos científicos na atualidade, com foco nos portais eletrônicos. Assim sendo, como forma de promover melhores discussões para a pesquisa a ser realizada, este artigo, de natureza preliminar, objetiva demonstrar a importância da comunicação científica no desenvolvimento das ciências e o papel desempenhado pelos periódicos científicos nesse processo. Nesse contexto, delineiam-se os seguintes objetivos específicos, a saber: 1 - definir e caracterizar o processo de comunicação científica; 2 - relacionar o processo da comunicação com o desenvolvimento das ciências; e 3 - discorrer o papel desempenhado pelos periódicos científicos no âmbito da comunicação científica, apresentando alguns desafios e expectativas inerentes a esse tipo de comunicação.

Como metodologia, adotou-se a pesquisa descritiva e bibliográfica, com abordagem dedutiva, utilizando como materiais de consulta: livros, artigos científicos e trabalhos acadêmicos (teses e dissertações) que versam sobre a temática em apreço. O estudo caracteriza-se como descritivo, pois descreve as características de determinados objetos de pesquisa, qual seja: a comunicação científica e os periódicos científicos, expondo aspectos conceituais e históricos. Adota procedimentos bibliográficos, uma vez que recorre, como objetos de investigação, a materiais bibliográficos, representados por livros, artigos e trabalhos científicos, desenvolvidos em universidades. Por fim, sustenta-se na abordagem dedutiva, pois apresenta a temática de pesquisa, expondo, ao longo do texto, desde assuntos mais genéricos, tais como aspectos relativos ao processo científico, até assuntos mais específicos, tais como os periódicos científicos como canais formais de comunicação científica.

\section{PERCURSO METODOLÓGICO}

No intuito de descrever os objetos de pesquisa, qual sejam o processo de comunicação científica e o papel dos periódicos científicos, o instrumental metodológico utilizado contemplou a busca a diversas fontes de informação que dissertam sobre os objetos de pesquisa mencionados. Optou por fontes de informação originadas a partir do processo de pesquisa realizada em universidades e armazenada nas bibliotecas dessas instituições (no que se refere aos livros e trabalhos acadêmicos) ou publicada em revistas e eventos científicos (quanto aos artigos analisados).

Por isso, realizou-se a consulta a livros, teses e dissertações, estando esses materiais armazenados em catálogos digitais de bibliotecas universitárias brasileiras, como também foram consultados artigos indexados em bases de dados. A escolha por esses ambientes de busca deveuse ao fato de que as universidades, por meio de suas bibliotecas, e com o uso de bases de dados para divulgação e armazenamento da produção científica, colocam-se a serviço do ensino, da pesquisa e da extensão, logo, as fontes consultadas nesses ambientes são fruto do intenso trabalho 
metodológico e fidedigno, o que confere cientificidade e credibilidade às fontes consultadas.

Outro fato que justifica a seleção das fontes no catálogo das bibliotecas universitárias e nas bases de dados, diz respeito à crença de que, as universidades oferecem diversos cursos, diluídos nas mais diversificadas áreas do conhecimento humano. Assim, em virtude de a comunicação científica ser um processo que abrange todas as áreas científicas, é bem verdade que nos acervos das bibliotecas universitárias, sejam encontrados materiais sobre esse tema, uma vez que esses materiais servem para auxiliar o trabalho científicos dos pesquisadores que atuam nesses espaços, tais como professores, alunos, dentre outros agentes que se dedicam ao processo de investigação e divulgação da ciência.

As bases de dados analisadas foram a Base de Dados em Ciência da Informação (BRAPCI) e a Scientifi c Electronic Library (SCIELO). Nos catálogos eletrônicos das bibliotecas universitárias e das bases de dados, utilizaram-se os seguintes descritores: "comunicação científica" e "periódicos científicos". Devido à multiplicidade de itens recuperados, a seleção deles para compor a amostra de pesquisa foi realizada por meio da leitura ao título e ao resumo de cada item, atividade essa que permitiu analisar, tão somente, os itens que estavam relacionadas à temática de pesquisa contemplada neste artigo.

Após seleção das fontes oriundas dos diversos acervos bibliográficos investigados, constataram-se as seguintes publicações a serem analisadas:

- No que se refere aos livros: Campello (2003), Fachin e Hillesheim (2006), Houghton (1975), Meadows (1999), Mueller (2003a, 2003b) e Ziman (1968);

- Quanto aos artigos: Garrido e Rodrigues (2010), Garvey e Griffith (1972), Mueller (2006), Oliveira (2008), Packer (2005), Rodrigues e Fachin (2008), Schweitzer, Rodrigues e Rados (2011), Targino (2000, 2001).

- No que tange aos trabalhos acadêmicos (teses e dissertações): Bomfá (2009), Costa (2007), Crespo (2005), Marra (2015), Oliveira (2006), Samagaia (2016), Souza (2012) e Teixeira (2016).

Com efeito, a partir dessa amostra de pesquisa, as publicações foram analisadas de modo a fornecerem informações sobre o processo de comunicação científica no âmago do desenvolvimento científico e o papel dos periódicos no processo comunicativo. Assim, os assuntos foram abordados ao longo deste texto, em consonância com os objetivos previamente formulados, permitindo, dessa forma, um delineamento sistematizado das reflexões apresentadas.

\section{REFLETINDO SOBRE A COMUNICAÇÃO CIENTÍFICA NO DESENVOLVIMENTO DAS CIÊNCIAS}

O processo de comunicação compreende uma série de procedimentos realizados por indivíduos, haja vista permitir que informações possam ser transferidas, desencadeando a compreensão e concretização de novos conhecimentos. Tal processo envolve diferentes agentes, como também diversos mecanismos, canais e códigos que facilitam a transferência ou fluxo das informações. Se esse processo realiza-se no âmbito científico, em que as informações perpassam as atividades científicas realizadas por pesquisadores das mais diversas áreas do saber humano, consolida-se a comunicação científica (TARGINO, 2000).

A comunicação científica corresponde, portanto, a uma das características ou fazeres essenciais das ciências, pois é graças a ela que os pesquisadores divulgam os resultados de suas pesquisas, de modo que possam ser validados por outros pesquisadores, como também possam ser divulgados e compartilhados, permitindo, nesse sentido, a ampliação e aperfeiçoamento das descobertas (MUELLER, 2003a).

No entendimento de Targino (2000), a ciência é sustentada por um processo de rigorosa metodologia, permeado por um fluxo de informações de natureza complexa, cujo objetivo dessa complexidade é viabilizar maior consistência e aceitação dos resultados obtidos. Sendo assim, ao se comunicar, os cientistas comungam os esforços individuais dos membros das 
comunidades científicas, transferindo continuamente informações com seus pares, de modo a emitir quanto receber, reciprocamente, informações relativas ao processo de investigação científica.

Em grande parte, o que caracteriza o trabalho científico, por conseguinte, os métodos e os mecanismos de comunicação utilizados pelas ciências, diz respeito à validação e aceitação dos procedimentos utilizados no processo de investigação. Os métodos utilizados devem ser sistemáticos e seguros, fato esse que viabiliza confiabilidade aos resultados adquiridos, tendência que diferencia o conhecimento científico das outras modalidades de conhecimento (MUELLER, 2003a; TARGINO, 2000; ZIMAN, 1968). Em virtude desses rigores e do cumprimento de padrões,

[...] a confiabilidade [torna-se], portanto, uma das características mais importantes da ciência, pois a distingue do conhecimento popular, não científico. Para obter confiabilidade, além da utilização de uma rigorosa metodologia científica para a geração de conhecimento, é importante que os resultados obtidos pelas pesquisas de um cientista sejam divulgados e submetidos ao julgamento de outros cientistas, seus pares (MUELLER, 2003a, p. 21).

No processo de investigação científica, os cientistas utilizam técnicas, métodos, experimentos, teorias e princípios específicos, os quais permitem a validação das descobertas. Ao ser posto para avaliação e sua devida aceitação pelos pares, os rigores científicos passam a ser utilizados por outros pesquisadores, de modo que as comunidades científicas vão sendo sustentadas por um trabalho coletivo, de compartilhamento e renovação do conhecimento (MEADOWS, 1999).

Corroborando com as ideias de Meadows (1999), Targino (2000, p. 12) afirma que os cientistas devem se embasar em determinadas escalas de valor ao exercerem as atividades científicas, tendência essa que caracteriza a ciência como uma atividade meramente imparcial. Para tanto, os resultados obtidos nas pesquisas devem ser analisados por meio da objetivação, o que permite reconhecer o conhecimento "[...] como reconstrução, como inserção que o pesquisador faz no seu objeto de estudo, via teorização e técnicas que o permitem recortar e esculpir. Não se trata de neutralidade [...]".

Observa-se, nesse contexto, a árdua interação que existe entre os pesquisadores, sobretudo no que se refere à aceitação ou não de determinados valores e perspectivas, os quais são comungados por grupos de pesquisadores inerentes a áreas específicas de conhecimento (MEADOWS, 1999; TARGINO, 2000, 2001). Como resultado dessa interação e do trabalho científico, tem-se a formalização da produção científica dos campos científicos, sendo necessário, para essa formalização, um intenso processo de avaliação, consolidando o fluxo da comunicação científica (MUELLER, 2003a).

O fluxo da comunicação entre pesquisadores é de grande contribuição para garantir o aperfeiçoamento das pesquisas, bem como para promover as características básicas da ciência, sobretudo no que se refere à legitimidade, à confiabilidade e consistência. Sendo assim, segundo Mueller (2003a), modelos de comunicação tem sido considerado como tema pertinente de pesquisa, haja vista que esses modelos demonstram a tramitação de todo o percurso investigativo, desde a formalização das ideias pelos pesquisadores, até a divulgação final dos resultados, com a publicação do que foi descoberto.

Para Garvey e Griffith (1972), a comunicação científica perpassa um processo sistêmico, com a participação de diversos personagens, os quais unem esforços no sentido de validar, aperfeiçoar e disseminar as pesquisas, contribuindo, como resultado final, para o desenvolvimento das diversas áreas científicas.

Desse modo, ao longo do percurso científico, os resultados parciais oriundos dos 
procedimentos metodológicos são registrados em canais formais, por meio de trocas de informações entre pesquisadores. Após essa etapa, os resultados, ainda em fase preliminar, são publicados no formato de relatórios, sendo enviados a editores, a fim de serem submetidos a apreciação por pares, por conseguinte, sua publicação no formato de livros ou periódicos. Após sua validação pela comunidade científica, a pesquisa é publicada e, por conseguinte, indexada em índices e bases de dados, para, a partir dessa disseminação, ser utilizada para fomentar outras pesquisas, o que lhe confere maior legitimidade (GARVEY; GRIFFITH, 1972).

O modelo apresentado pelos autores supracitados é corroborado por Packer (2005), contudo, esse autor defende a necessidade de ampliação do fluxo da comunicação científica, sobretudo com a incorporação das tecnologias digitais como principais canais de divulgação científica.

A comunicação científica clássica, em suporte papel, realiza-se por meio de fluxos de trabalho e informação estruturados sobre uma sequência de instâncias distantes fisicamente, onde ocorrem eventos específicos, separados no tempo e realizados por diferentes atores. Ao longo das instâncias, o fluxo de informação e trabalho que realizam os diferentes atores (autor, editor, revisor, indexador, bibliotecário, usuário-leitor) é conduzido por meio de documentos em papel que são transportados fisicamente de uma instância a outra (PACKER, 2005, p. 251).

Para esse autor, a comunicação científica sustenta-se por um contínuo fluxo de informações, o qual inicia-se com a criação do manuscrito, perpassando as etapas de avaliação e editoração, para, após sua publicação, os documentos são sistematizados em acervos impressos, normalmente acoplados a bibliotecas e centros de documentação, o que despertou a participação do trabalho bibliotecário na organização das coleções de livros e periódicos.

No decorrer do fluxo informacional que sustenta a comunicação científica,

[...] a biblioteca, ou suas versões na forma de centros de documentação ou centros de informação, representa a penúltima instância de intermediação do texto e os seus usuários. A biblioteca é a instância que dá sustentação e democratiza o fluxo de informação ao funcionar como um repositório de publicações organizadas e preservadas para o seu uso repetido (PACKER, 2005, p. 252).

Contudo, a partir do uso das tecnologias digitais, o processo comunicativo, como também, as formas de armazenamento, acesso e uso das publicações científicas, são facilitados, sobretudo no que se refere às limitações de tempo e de espaço, dificuldades essas presentes no contexto do fluxo tradicional de comunicação científica (PACKER, 2005).

A esse respeito, Mueller (2003a, p. 24) disserta que as tecnologias digitais contribuem no avanço das ciências, como também acarreta benefícios no processo comunicativo. Isso porque, nos últimos anos, a partir da evolução tecnológica "[...] novos formatos e canais de comunicação se tornaram disponíveis, expandindo de maneira nunca vista as possibilidades da comunicação e eliminando barreiras geográficas [...]".

A evolução da tecnologia está estritamente relacionada à evolução científica, de modo que não é possível dissociar desenvolvimento científico e tecnológico. Da mesma forma, esse desenvolvimento repercute, de forma geral, no desenvolvimento socioeconômico das nações. Portanto, não resta dúvida de que, quem mais produz em ciência e tecnologia é quem mais avança no processo desenvolvimentista global (MEADOWS, 1999; TARGINO, 2000, 2001).

Em linhas gerais, percebe-se que a comunicação científica constitui o pilar que sustenta as práticas científicas, de modo que, é possível realizar ciência e garantir o avanço e melhoria 
das descobertas quando são formalizados fluxos bem definidos e padronizados de comunicação (MEADOWS, 1999; SCHWEITZER; RODRIGUES; RADOS, 2011).

Para Meadows (1999, p. 7),

A comunicação situa-se no próprio coração da ciência. É para ela tão vital quanto a própria pesquisa, pois a esta não cabe reivindicar com legitimidade este nome enquanto não houver sido analisada e aceita pelos pares. Isso exige, necessariamente, que seja comunicada. Ademais, o apoio às atividades científicas é dispendioso, e os recursos financeiros que lhe são alocados serão desperdiçados a menos que os resultados das pesquisas sejam mostrados aos públicos pertinentes. Qualquer que seja o ângulo pelo qual o examinemos, a comunicação eficiente e eficaz constitui parte essencial do processo de investigação científica.

Schweitzer, Rodrigues e Rados (2011) defendem que a comunicação contribui para garantir o avanço das ciências, pois é por meio dela que as pesquisas são desenvolvidas com maior consistência, uma vez que as ideias, ao serem compartilhadas e, ao mesmo tempo, redefinidas por pesquisadores de renome em uma dada área de conhecimento, resultam-se melhorias na forma como os métodos são empregados e os resultados analisados, garantindo, dessa forma, conclusões precisas, confiáveis e inovadoras.

$\mathrm{Na}$ visão de Mueller (2006), o ato de comunicar confere aos cientistas estratégias de melhoria de suas ideias. Além disso, segundo essa autora, a comunicação não viabiliza, apenas, a disseminação dos resultados, como também, coloca a pesquisa em processo de avaliação, mas garante que os pesquisadores aprimorem e redefinam seus objetivos de pesquisa, em face dos questionamentos e recomendações advindas dos pares e demais envolvidos com a atividade científica.

Por constituir-se como um processo complexo, o ato de comunicar exige dos cientistas o cumprimento de normativas, como também o estabelecimento de canais (formais e informais) de comunicação, que podem se manifestar na forma oral, como acontece nas reuniões e nos eventos, como também a comunicação também pode se apresentar na forma escrita ou documentada, por exemplo, nos relatórios de pesquisas, por meio da publicação de livros e artigos em periódicos científicos (MUELLER, 2003a, 2006).

Devido à importância no desenvolvimento das ciências, e atrelado à complexidade inerente ao processo de comunicação científica, esse tipo de comunicação é comungada por todos os cientistas de todas as áreas do conhecimento. Trata-se, portanto, de uma prática primordial no trabalho científico. Sendo assim, os cientistas estabelecem em seus domínios e áreas específicas de conhecimento, um sistema de comunicação, o qual funciona, grosso modo, como a veia-mestra, ou melhor, a infraestrutura que sustenta as atividades que permeiam a pesquisa, contemplando desde as ideias inicias aos resultados finais, os quais são disponibilizados para acesso e uso da comunidade científica e para a sociedade em geral (MUELLER, 2006; SAMAGAIA, 2016).

A tramitação das informações ao longo do fluxo de comunicação científica permite, além do aprimoramento e construção coletiva do conhecimento (PACKER, 2005), que as pesquisas realizadas obedeçam ao crivo do ineditismo, ou seja, para Mueller (2006), ao ser comunicada e avaliada, o autor receberá contribuições das mais diferenciadas do público-alvo, como também, as contribuições poderão evitar redundâncias e preservando a autoria dos estudos desenvolvidos.

Na visão de Ziman (1968), a legitimidade das pesquisas é oriunda do processo de validação e divulgação das pesquisas, sendo que, no decurso do fluxo comunicacional, os cientistas valem-se da publicação dos resultados, de modo que suas pesquisas possam ser testadas e aprimoradas. A publicação dos resultados, sejam eles de natureza parcial ou final, 
são disseminadas por meio de um processo de comunicação, que pode ser realizado de maneira formal quanto informal.

A comunicação informal, a qual utiliza como meio de divulgação os chamados canais informais, contempla, normalmente, comunicações de aspecto mais pessoal ou que se referem a pesquisas ainda não concluídas, como pesquisa em andamento, certos trabalhos de congresso, dentre outras. Por sua vez, no que se refere à comunicação formal, são utilizados mecanismos de comunicação mais amplo, com processo de avaliação mais sistematizado e rigoroso, gerando, como consequência, as publicações no formato de relatórios, relatos de pesquisa, livros ou artigos apresentados em eventos e publicados em revistas (MUELLER, 2003a).

De maneira similar, o estudo de Fachin e Hillesheim (2006) também discorre acerca do processo de comunicação entre cientistas, o qual pode ser realizado por meio de canais formais quanto informais, canais esses que estão diluídos no intenso fluxo da comunicação científica. No entendimento dessas autoras, os canais formais são considerados como principais mecanismos de divulgação pelo fato de eles tornarem as informações científicas passíveis de tratamento, registro, padronização e, por fim, recuperação. Dentre os mais importantes canais de comunicação científica, de natureza formal, destaca-se, segundo Fachin e Hillesheim (2006), os periódicos científicos, estimados como os principais meios de divulgação das investigações, sobretudo pela rapidez na avaliação e divulgação dos resultados. Portanto, ao serem analisados no âmbito acadêmico, os periódicos científicos passam a ser considerados como principais instrumentos de divulgação da produção científica, fato esse que viabiliza e amplia o papel desempenhado por esses canais no desenvolvimento científico em todas as áreas do conhecimento.

\subsection{O PAPEL DOS PERIÓDICOS CIENTÍFICOS NO PROCESSO DA COMUNICAÇÃO E NO DESENVOLVIMENTO CIENTÍFICO}

No decurso do fluxo da comunicação científica, à medida que os resultados vão sendo concretizados, eles são submetidos para avaliação pela comunidade científica, e, ao serem aceitos, tornam-se legítimos e confiáveis, fato esse que viabiliza a publicação desses resultados, principalmente em canais formais, de modo que as descobertas cheguem ao alcance do públicoalvo, desencadeando, dessa forma, a disseminação das pesquisas realizadas (MARRA, 2015).

A publicação das pesquisas, independente do canal de comunicação a que é submetida, quanto também do formato em que se apresenta, seja ele impresso ou digital, tem como um dos seus maiores objetivos, garantir, de modo geral, a visibilidade dos resultados obtidos. Na verdade, trata-se de um processo de divulgação e, ao mesmo tempo, oportuniza-se condições para que os resultados possam ser utilizados por outros pesquisadores, tendo em vista a ampliação do conhecimento (BOMFÁ, 2009; MARRA, 2015; SOUZA, 2012).

De acordo com Fachin e Hillesheim (2006), Marra (2015) e Mueller (2003a), os resultados parciais das pesquisas, normalmente, são publicados em canais informais de comunicação, em que se consolida um diálogo constante entre pesquisadores de uma mesma área do conhecimento. Por sua vez, os resultados finais, em que as pesquisas já se encontram em processo de finalização, são divulgados em canais formais de comunicação, seja no formato de livros, quanto no formato de artigos de periódicos, por exemplo.

Campello (2003) discorre sobre a morosidade no processo de avaliação das pesquisas submetidas para publicação em livros quanto em periódicos. Esse fato despertou a criação de novos canais, a maioria considerada como comunicação informal, em que os resultados preliminares passam a ser compartilhados, provocando a melhoria da pesquisa. Assim, as pesquisas em andamento são permeadas por publicações preliminares, em que pese a troca de informações entre cientistas, sendo que as tecnologias digitais contribuíram para a formação de novos canais, como as listas de discussões, os blogs, entre outros canais de interação.

Mueller (2003b) descreve que os livros correspondem a um tipo de publicação muito 
utilizado por cientistas, sendo considerada a mais antiga forma de divulgação das pesquisas científicas, juntamente com a comunicação oral e cartas escritas entre os cientistas. Embora essa forma de publicação tenha acompanhado a evolução das ciências, desde os primórdios da civilização, perdurando ainda em nossos dias - o que lhe é conferido o seu grandioso valor no desenvolvimento científico - o problema dos livros, segundo Mueller (2003b), está na acumulação de conhecimento existente nessas publicações, as quais são concretizadas apenas com os resultados finais das pesquisas, fato esse que despende muito tempo desde o nascimento da pesquisa até sua divulgação.

Com efeito, as grandes revoluções que sucederam ao século XV desencadearam rápidas transformações, promovendo altos índices de obsolescência, em todas as instâncias e segmentos sociais (CAMPELLO, 2003). No âmago científico, segundo Mueller (2003b) e Schweitzer, Rodrigues e Rados (2011), a gênese da ciência moderna, aliado ao desenvolvimento das tecnologias digitais, são os maiores fatores que contribuíram para o nascimento de uma forma de comunicação mais rápida e que permitisse a publicação dos resultados parciais, de modo que esses resultados passam a ser publicados periodicamente, contemplando todas as fases da pesquisa. Assim,

[...] com o advento da ciência moderna, o importante passou a ser a comunicação rápida e precisa sobre uma experiência ou observação específica, que permitisse a troca também rápida de ideias e a crítica entre todos os cientistas interessados no assunto em questão. Isso provocou a necessidade de um novo meio de comunicação, de alcance mais amplo que a comunicação oral e a correspondência pessoal, bem mais rápido que os livros e tratados: o periódico científico (MUELLER, 2003b, p. 73-74).

Ao contrário das formas tradicionais de publicação das pesquisas científicas, como os livros, os periódicos correspondem a veículos de comunicação modernos, que tiveram suas raízes no final do século XVII, sustentados por corpo editorial e avaliativo, que une esforços no sentido de permitir a publicação das edições, obedecendo-se a determinados períodos de tempo, os quais podem ser regulares ou não. Como primeiros periódicos científicos de que se tem notícia, citam-se o Journal de Sçavans, publicado em Paris, e o Philosophical Transactions, publicado em Londres (MEANDOWS, 1999).

Essas formas de comunicação representaram uma mudança radical na rapidez das publicações científicas, contribuindo decisivamente para o desenvolvimento das ciências e, por conseguinte, acarretando mudanças no processo de comunicação científica. Essas mudanças têm sido intensificadas, sobremaneira, a partir do uso das tecnologias digitais, o que desencadeou o aparecimento do periódico científico eletrônico (COSTA, 2007; CRESPO, 2005; OLIVEIRA, 2008).

Precisamente, no ano de 1965, é publicado o Journal de Sçavans, em suporte papel e destinado a divulgar matérias em todas as áreas científicas. Juntamente com o Philosophical Transactions, esses primeiros periódicos impressos eram mantidos por associações profissionais, mas, no decorrer dos tempos, novos periódicos foram surgindo, sendo mantidos também por instituições de pesquisas e de formação profissional. Na década de 1970, realizase as primeiras conferências para formalização dos periódicos eletrônicos, os quais, a princípio, manteriam os formatos impressos e eletrônicos, com tendência a estabelecerem, no futuro, tão somente, o formato eletrônico (OLIVEIRA, 2006, 2008).

Todavia, mesmo com as mudanças de suporte, do impresso ao eletrônico, e contemplando, também, em alguns casos, a versão híbrida, segundo Mueller (2003b, 2006), em linhas gerais, o fluxo da comunicação científica, o corpo editorial, avaliativo e consultivo, as características de validação, credibilidade, imparcialidade, confiabilidade, legitimidade, dentre outras, são aspectos que, praticamente, tornaram-se inalteráveis, mesmo com as mudanças de 
formato.

De qualquer forma, há de se convir que os periódicos científicos revolucionaram todas as áreas de conhecimento, ao viabilizar novas estratégias para comunicar as novidades científicas que estão sendo investigadas. A aceitação dessa nova forma de veicular a comunicação científica foi bem-vinda a ponto de o periódico ser considerado o principal meio de divulgação das pesquisas científicas (FACHIN; HILLESHEIM, 2006). Desse modo,

[...] os periódicos científicos constituem-se em elementos importantes e fundamentais na disseminação e evolução da ciência e tecnologia em um país, pois por meio deles, são divulgados os resultados das pesquisas realizadas, sobre os mais variados assuntos. São os suportes mais utilizados para recuperar e manter-se atualizado na informação científica e tecnológica (FACHIN; HILLESHEIM, 2006, p. 15, grifo nosso).

Com efeito, sendo os periódicos científicos propulsores do crescimento e disseminação do conhecimento no Brasil e no mundo, passaram e continuam a passar por transformações, reestruturações e adaptações, principalmente, a partir dos avanços tecnológicos presentes em cada época, provocando, dessa forma, um aumento excessivo no número de periódicos nas diversas áreas de conhecimento (FACHIN; HILLESHEIM, 2006).

No entendimento de Mueller (2003b, 2006), passados mais de trezentos anos após o seu nascimento, os periódicos científicos constituem a forma mais comum de se publicar os resultados das investigações científicas, sendo que a forma impressa está sendo a cada dia substituída pelos formatos eletrônicos. A incorporação das novas tecnologias desencadeou, além de novas formas de preservação, acesso e uso às informações contidas nos artigos, também viabilizou a formalização de novos ambientes para armazenar esse tipo de publicação, tal como acontece com os novos modelos criados a partir do ambiente digital, tal como os repositórios digitais e os portais eletrônicos de periódicos científicos, como nos ensina Garrido e Rodrigues (2010), Rodrigues e Fachin (2008) e Samagaia (2016).

Destarte, evidencia-se que, as transformações viabilizadas com o aparecimento do periódico científico e suas multiplicidades de formato acarretam novidades ao processo científico, ocasionando mudanças, principalmente no que se refere à rapidez das divulgações, como também integrando os membros da comunidade científica, criando novas formas de aproximação entre cientistas e público-alvo, como também conferindo maior visibilidade das atividades e descobertas científicas (BOMFÁ, 2009; OLIVEIRA, 2008).

A partir do uso dos periódicos científicos, mudanças radicais foram viabilizadas ao processo de comunicação científica, principalmente pelo fato desses canais de comunicação terem que cumprir com prazos específicos, a maioria das vezes, em intervalos regulares, para viabilizar a publicação de novas edições, contendo um conjunto de pesquisas, a maioria em formato de artigos, tendo em vista permitir que as descobertas científicas sejam acessadas pelos interessados (MEANDOWS, 1999).

A origem dos periódicos eletrônicos, embora garantiu a permanência das características essenciais dos periódicos impressos, desencadeou uma nova configuração ao fluxo da comunicação científica transmitida pelas publicações periódicas. Esse fato demonstra a necessidade de se desenvolver novos estudos acerca dos periódicos eletrônicos, de modo que as questões sejam bem definidas, eliminando problemas eventuais que possam surgir ao disponibilizar as informações no ambiente digital, tais como exemplos, a questão da preservação digital, o acesso livre ao conhecimento e as questões inerentes aos direitos autorais (COSTA, 2007; CRESPO, 2005; MUELLER, 2006).

$\mathrm{Na}$ atualidade, é bem verdade que os periódicos em formato eletrônico têm se sobressaído em relação aos periódicos impressos, de modo que muitos já se encontram apenas no formato digital (OLIVEIRA, 2008). Nesse âmago, Fachin e Hillesheim (2006) dissertam 
que com os recursos e formatos oriundos das tecnologias digitais, os periódicos utilizam de um ambiente diversificado e interativo para editar e disseminar a informação científica, passando a ser aceito como um novo veículo de formalização da produção científica e de sua disseminação.

Portanto, as tecnologias digitais contribuíram para aumentar a capacidade dos periódicos em promover maior visibilidade das descobertas científicas e, por conseguinte, ampliar, agilizar e integrar a comunicação entre os diversos atores envolvidos com a produção de conhecimento de uma determinada área do saber humano (BOMFÁ, 2009). Assim,

[...] resgata-se, nesse instante, a importância da comunicação científica como veículo propulsor da troca de informações e de cooperação entre os pares, na construção e evolução rápida do conhecimento e edição dos periódicos científicos, que representam o registro oficial, sendo a sua preservação essencial para a continuidade do ciclo evolutivo (FACHIN; HILLESHEIM, 2006, p. 17).

A respeito dos novos desafios e tendências impostas pelo periódico científico ao processo de comunicação científica e ao próprio desenvolvimento das ciências, Mueller (2003b, 2006) acredita que deve haver o monitoramento constante desses novos canais de divulgação, sendo essa uma tarefa essencial para os profissionais interessados na comunicação científica, pois as opções disponíveis aumentam e se aprimoram, o mercado evolui com rapidez, o que é novo tem vida cada vez mais curta, sendo rapidamente, substituído por novos produtos e serviços, circunstâncias essas que requerem decisões complexas.

Portanto, o uso das plataformas digitais para acomodar as publicações periódicas acometeu mudanças no fluxo da comunicação científica, como também provocou aproximações e interações entre os diversos agentes que permeiam o processo científico. Desse modo,

[...] a partir do formato on-line, baseado em uma estrutura de redes de computadores e no acesso livre ou por senhas às instituições de ensino e de pesquisa, permitido pelo uso da internet, fazem com que o periódico científico passe a ter uma grande oportunidade de expansão, com redução de custos, agilidade de entrega, disponibilização de conteúdos e a constante troca de informações entre os pares (FACHIN; HILLESHEIM, 2006, p. 38-39).

A contribuição do periódico científico é inegável para o desenvolvimento das ciências, em especial, para o aprimoramento da comunicação entre pesquisadores e a divulgação das pesquisas para o público em geral, desencadeando melhorias para a sociedade. Mesmo diante das valiosas contribuições que esses meios de comunicação proporcionam, alguns problemas se fazem presentes, tal como a proliferação do número de títulos dos periódicos, provocando, como consequência, duplicidade de artigos sobre mesmos assuntos (MUELLER, 2003b).

Além disso, no que se refere aos problemas ou desafios inerentes aos periódicos científicos, Fachin e Hillesheim (2006) destacam as dificuldades de padronização no formato das publicações, como também dispersão nas formas e modelos de organização dessas publicações, fatores esses que dificultam a recuperação, acesso e uso dos diversos títulos existentes.

Costa (2007), Crespo (2005), Mueller (2006) e Oliveira (2008) mencionam que, com a migração para o formato eletrônico, os periódicos adquirem inúmeras funcionalidades, resolvendo alguns problemas inerentes ao formato físico, no entanto, promovem o aparecimento de outros desafios, principalmente no que se refere à forma de acesso dessas publicações pelos leitores, o que reconfigura o papel desempenhado pelas editoras, sendo que essa tendência tem sido bem vista como uma oportunidade de garantir o acesso universal ao conhecimento científico, independente das condições socioeconômicas de cada nação.

No que se refere aos novos papéis desempenhados pelas editoras, observa-se uma 
mudança de configuração editorial, uma vez que o fluxo da comunicação científica deixa de ser realizado (gerenciado) unicamente pela editora, mas passa a ser realizado nas plataformas eletrônicas, interagindo os diversos atores participantes, por meio dos recursos interativos do ambiente digital. Assim, segundo Targino (2001) e Teixeira (2016), considerando os editores de periódicos que não aderem ao movimento de acesso livre ao conhecimento, novos nichos de mercado são vislumbrados, com a participação de diversos profissionais que passam a contribuir para a comercialização dos títulos publicados.

Quanto aos periódicos que aderem ao movimento do acesso aberto, segundo Marra (2015), Oliveira (2008, p. 73) e Souza (2012), observa-se um movimento massificado e intenso em prol da consolidação do acesso livre às publicações periódicas. Para a primeira autora,

\begin{abstract}
A grande contribuição da disponibilização de periódicos de acesso aberto foi possibilitar a equidade de acesso à informação entre países desenvolvidos e em desenvolvimento, contribuindo para minimizar as diferenças geográficas e financeiras dos pesquisadores localizados em regiões distantes dos centros de pesquisa mais avançados (OLIVEIRA, 2008, p. 73).
\end{abstract}

Em síntese, a partir do uso dos periódicos científicos, a comunicação científica se intensifica, desencadeando inúmeras contribuições, sobretudo no que se refere à rapidez na divulgação das pesquisas, como também, a aproximação entre os diversos atores envolvidos no processo de comunicação e divulgação da ciência. Esse fato justifica a importância que esse meio de comunicação tem desempenhado no desenvolvimento das ciências, sendo a forma de publicação e comunicação científicas mais utilizadas em todas as áreas do conhecimento (MUELLER, 2003b).

Com o uso das tecnologias digitais, por conseguinte, o surgimento do periódico eletrônico, segundo Mueller (2006), muitos problemas inerentes ao formato impresso foram solucionados, muitos ainda carecem de soluções, como também, observa-se o aparecimento de outros desafios, o que requer a continuidade das pesquisas sobre essa temática, sobretudo por haver uma reconfiguração em todo o sistema de comunicação científica e a redefinição dos papéis desempenhados pelos diversos profissionais envolvidos com a produção e disseminação do conhecimento científico.

\title{
4 DISCUTINDO ALGUNS RESULTADOS
}

Por meio da análise às diversas obras investigadas neste artigo e considerando os objetivos previamente formulados, é possível descrever alguns resultados alcançados, tendo em vista três diferentes aspectos, a saber: 1 - definição e características da comunicação científica; 2- relações existentes entre a comunicação científica e desenvolvimento científico; e, 3 - as contribuições dos periódicos para a comunicação científica e os principais desafios e expectativas referentes a esse meio de comunicação.

O processo de comunicação científica constitui um conjunto de procedimentos, realizados por diferentes agentes, os quais interagem-se entre si, de modo a garantir a troca de informações entre cientistas, tendo em vista proporcionar validação, confiabilidade, credibilidade, e, como consequência, o aprimoramento na produção de conhecimento. Referese a um processo complexo, o qual requer o estabelecimento de um sistema integrado e processual, o qual viabiliza a formação de fluxos de comunicação entre todos os envolvidos no processo científico. De modo geral, essa constatação é corroborada pela maioria dos estudos analisados, sendo analisada com mais intensidade por Bomfá (2009), Campello (2003), Garvey e Griffith (1972), Houghton (1975), Meadows (1999), Mueller 2003a, Mueller 2006, Packer (2005), Targino (2000), Teixeira (2016) e Ziman (1968).

No que se refere às relações entre comunicação científica e o desenvolvimento das ciências, evidencia-se que, ao se comunicar, os cientistas socializam ideias, de modo a validar, 
refutar ou aprimorar os resultados obtidos nas pesquisas realizadas. Além disso, a comunicação também viabiliza a disseminação das descobertas científicas, o que promove a interação entre pesquisadores, como descrito nos estudos de Garvey e Griffith (1972), Houghton, (1975), Meadows (1999), Rodrigues e Fachin (2008), Schweitzer e Rodrigues e Rados (2011), Targino (2000) e Targino (2001).

Quanto às questões relativas às características dos periódicos científicos e a contribuição no processo de comunicação científica, pode-se afirmar que os periódicos constituem veículos de comunicação, os quais promovem maior rapidez na validação e disseminação dos resultados das pesquisas, como também maior integração entre os diversos personagens envolvidos com a gestão das publicações periódicas. Portanto, os periódicos, originados a partir do desenvolvimento da ciência moderna, provocaram uma evolução no processo comunicativo, e, por decorrência, passaram a ser considerados como os principais meios de comunicação e publicação das descobertas científicas em todas as áreas de conhecimento. Esses resultados são apresentados nos trabalhos de Bomfá (2009), Fachin e Hillesheim (2006), Garrido e Rodrigues (2010), Mueller (2003b), Oliveira (2006, 2008), Rodrigues e Fachin (2008), Samagaia (2016) e Targino (2001).

Importante considerar que, mesmo com as contribuições dos periódicos no aprimoramento da comunicação científica como também no desenvolvimento científico, na atualidade, percebem-se alguns desafios e presumem-se algumas expectativas, sobretudo com a incorporação das tecnologias digitais, as quais viabilizam a disponibilização dos periódicos em ambientes digitais. Assim, a maioria dos periódicos científicos já se encontra disponibilizada em plataformas digitais, sendo que as atividades editoriais e comunicativas, como também a essência e objetivo dessas publicações, praticamente, permanecem as mesmas dos periódicos impressos. Os principais desafios que são impostos aos periódicos digitais dizem respeito à questão do acesso aberto, da preservação digital e dos direitos autorais. Por conseguinte, diversos estudos estão sendo realizados no sentido de ampliar as funcionalidades dessas publicações ao utilizarem das potencialidades oferecidas pelos recursos digitais. Essas reflexões são apresentadas nas obras de Costa (2007), Crespo (2005), Garrido e Rodrigues (2010), Mueller (2006), Oliveira (2008), Rodrigues e Fachin (2008), Schweitzer, Rodrigues e Rados (2011), Souza (2012), Targino (2001) e Teixeira (2016).

\section{CONSIDERAÇÕES FINAIS}

A investigação realizada em obras bibliográficas que versam sobre comunicação científica e periódicos científicos, em linhas gerais, enfatizou a importância da comunicação científica no desenvolvimento das ciências e o papel desempenhado pelos periódicos científicos nesse processo, os quais têm garantido rapidez e interação nas trocas de informação necessárias para viabilizar melhorais nas investigações e descobertas realizadas.

Os resultados alcançados permitiram concluir que os periódicos científicos continuam sendo os principais meios de comunicação científica utilizados em todas as áreas do conhecimento, sendo que o uso das tecnologias digitais contribui para melhorar o processo de comunicação, como também proporciona maior visibilidade das descobertas científicas e maior aproximação entre os diversos personagens envolvidos no processo de comunicação, disseminação e uso das informações científicas.

Para que o uso das tecnologias digitais nos periódicos científicos proporcionem melhorias à comunicação científica e ao desenvolvimento das ciências, faz-se necessária a realização de novas e constantes pesquisas, sobretudo no que se refere à segurança e preservação das informações disponibilizadas, como também, a questão dos direitos autorais. Além disso, estão em voga, estudos sobre modelos para construção de portais eletrônicos, como também, torna-se pertinente realizar pesquisas com foco na disseminação dessas publicações e a relações com os públicos-alvo, enfocando na estruturação das plataformas digitais e no comportamento e uso das informações pelos usuários. 


\section{REFERÊNCIAS}

BOMFÁ, Cláudia Regina Ziliotto. Modelo de gestão de periódicos científicos eletrônicos com foco na promoção da visibilidade. 2009. 238 f. Tese (Doutorado em Engenharia de Produção) - Programa de Pós-graduação em Engenharia de Produção, Universidade Federal de Santa Catarina, 2009.

CAMPELLO, Bernadete Santos. Pesquisas em andamento. In: CAMPELLO, Bernadete Santos; CENDÓN, Beatriz Valadares; KREMER, Jeannette Marguerite (Org.). Fontes de informação para pesquisadores e profissionais. 2. ed. Belo Horizonte: Editora UFMG, 2003. cap. 3, p. 49-54.

COSTA, Rubenildo Oliveira da. Análise do uso de periódicos científicos na transição do meio impresso ao eletrônico em dissertações e teses: o impacto do Portal de Periódicos Capes na produção do conhecimento. 2007. 143 f. Dissertação (Mestrado em Ciência da Informação) - Curso de Pós-Graduação em Ciência da Informação, Pontifícia Universidade Católica de Campinas, 2007.

CRESPO, Isabel Merlo. Um estudo sobre o comportamento de busca e uso de informação de pesquisadores da área de biologia molecular e biotecnologia: impactos do periódico científico eletrônico. 2005. 120 f. Dissertação (Mestrado em Comunicação) - Faculdade de Biotecnologia e Comunicação, Universidade Federal do Rio Grande do Sul, 2005.

FACHIN, Gleisy Regina Bories; HILLESHEIM, Araci Isaltina de Andrade. O periódico científico: padronização e organização. Florianópolis: Editora da UFSC, 2006.

GARRIDO, Isadora dos Santos; RODRIGUES, Rosangela Schwarz. Portais de periódicos científicos online: organização institucional das publicações. Perspectivas em Ciência da Informação, v. 15, n. 2, p. 56-72, maio/ago. 2010.

GARVEY, W. D. GRIFFITH, B. C. Communication and information processing within scientific disciplines: empirical findings for psychology. Information Storage and Retrieval, v. 8, n. 3, p. 123-136, 1972.

HOUGHTON, Bernard. Scientific periodicals: their historical development, characteristics and control. Hamden: Linnet Books, 1975.

MARRA, Patrícia dos Santos Caldas. Portais de periódicos científicos de acesso aberto nas universidades brasileiras. 2015. 139 f. Dissertação (Mestrado em Biblioteconomia) Departamento de Biblioteconomia, Universidade Federal do Estado do Rio de Janeiro, 2015.

MEADOWS, Arthur Jack. A comunicação científica. Brasília, DF: Briquet de Lemos, 1999.

MUELLER, Suzana Pinheiro Machado. A ciência, o sistema de comunicação e a literatura científica. In: CAMPELLO, Bernadete Santos; CENDÓN, Beatriz Valadares; KREMER, Jeannette Marguerite (Org.). Fontes de informação para pesquisadores e profissionais. 2. ed. Belo Horizonte: Editora UFMG, 2003a. cap. 1, p. 21-34.

O periódico científico. In: CAMPELLO, Bernadete Santos; CENDÓN, Beatriz Valadares; KREMER, Jeannette Marguerite (Org.). Fontes de informação para 
pesquisadores e profissionais. 2. ed. Belo Horizonte: Editora UFMG, 2003b. cap. 5, p. 7396.

A comunicação científica e o movimento de acesso livre ao conhecimento. Ciência da Informação, Brasília, DF, v. 35, n. 2, 2006.

OLIVEIRA, Érica Beatriz Pinto Moreschi de. Uso de periódicos científicos eletrônicos por docentes e pós-graduandos do Instituto de Geociências da USP. 2006. 140f. Dissertação (Mestrado) - Escola de Comunicações e Artes, Universidade de São Paulo, 2006.

Periódicos científicos eletrônicos: definições e histórico. Informação e Sociedade: Estudos, João Pessoa, v. 18, n. 2, p. 69-77, maio/ago. 2008.

PACKER, Abel Laerte. A construção coletiva da Biblioteca Virtual em Saúde. Interface Comunicação Saúde, Educação, v. 9, n. 17, p. 249-72, mar./ago. 2005.

RODRIGUES, Rosângela Schwarz; FACHIN, Gleisy Regina Bories. A comunicação científica e o uso de portais: estudo. In: ENCONTRO NACIONAL DE PESQUISA EM CIÊNCIA DA INFORMAÇÃO, 9, Anais Eletrônicos, São Paulo, Universidade de São Paulo, 2008.

SAMAGAIA, Rafaela Rejane. Comunicação, divulgação e educação científicas: uma análise em função dos modelos teóricos e pedagógicos. 2016. 354 f. Tese (Doutorado em Educação Científica e Tecnológica) - Programa de Pós-Graduação em Educação Científica e Tecnológica, Universidade Federal de Santa Catarina, 2016.

SCHWEITZER, Fernanda; RODRIGUES, Rosângela Schwarz; RADOS, Gregório Jean Varvakis. Comunicação científica e as tecnologias de informação e comunicação.

Comunicação \& Sociedade, ano 32, n. 55, p. 83-104, jan./jun. 2011.

SOUZA, Marylu Ferreira de. Comunicação da informação científica em novos espaços de memória. 2012. 148 f. Dissertação (Mestrado em Ciência da Informação) - Departamento de Ciência da Informação, Universidade Federal de Pernambuco, 2012.

TARGINO, Maria das Graças. Comunicação científica: uma revisão de seus fundamentos básicos. Informação e Sociedade: estudos, v. 10, n. 2, p. 1-27, 2000. Disponível em: < http://www.ies.ufpb.br/ojs/index.php/ies/article/view/326/248>. Acesso em: 15 dez. 2016. . Comunicação científica na sociedade tecnológica: Periódicos eletrônicos em discussão. Comunicação e Sociedade, v. 3, n. 1-2, p. 93-112, 2001.

TEIXEIRA, Danielle Tavares. Comunicação institucional e universidade: diretrizes para a divulgação científica no estado de Mato Grosso. 2016. 263 f. Tese (Doutorado em Comunicação Social) - Programa de Pós-Graduação em Comunicação Social, Universidade Metodista de São Paulo, 2016.

ZIMAN, John. Public Knowledge: the social dimension of science. London: Cambridge University Press, 1968. 